\title{
Health warnings on tobacco products: International practices
}

\author{
David Hammond, PhD, (1) Jessica L Reid, MSc.(2)
}

\section{Hammond D, Reid JL. Health warnings on tobacco products: International practices. Salud Publica Mex 2012;54:270-280.}

\begin{abstract}
Health warnings on tobacco products have emerged as a prominent area of tobacco control policy. Regulatory practice has rapidly evolved over the past decade to the point where health warnings on tobacco products continue to set international precedents for their size and comprehensiveness. The current paper provides a general review of current regulatory practices, including physical design features (such as size and location), message content (pictorial vs. text and content "themes), and regulatory considerations such as rotation period and other novel practices.
\end{abstract}

Key words: product labelling, tobacco, health policy, health communication

\author{
Hammond D, Reid JL. \\ Advertencias sanitarias en los productos de tabaco: \\ prácticas internacionales.
}

Salud Publica Mex 20I2;54:270-280.

\section{Resumen}

Las advertencias sanitarias en los productos de tabaco han llegado a ser una de las políticas públicas principales para el control del tabaco. A través de la última década las prácticas regulatorias han evolucionado mucho y varios países siguen impulsado cambios regulatorios importantes en términos del tamaño y carácter de las advertencias sanitarias que han implementado. Este ensayo resume las prácticas regulatorias actuales alrededor del mundo, incluyendo las características del diseño físico de la advertencia (es decir, tamaño y ubicación), sus contenidos (temas, pictogramas, textos) y otros factores regulatorios importantes (frecuencia de rotación y otras prácticas innovadoras).

Palabras clave: tabaco; política de salud; etiquetado de productos; comunicación para la salud
$\mathrm{H}$ ealth warnings on tobacco products have emerged as a prominent area of tobacco control policy. Regulatory practice has rapidly evolved over the past decade to the point where health warnings on tobacco products continue to set international precedents for their size and comprehensiveness. This chapter provides a general review of current regulatory practices.

\section{International standards: the WHO Framework Convention on Tobacco Control}

The World Health Organization (WHO) Framework Convention on Tobacco Control (FCTC), the world's first public health treaty, was adopted by the World Health Assembly in May 2003 and has since been ratified by more than 170 countries. ${ }^{1}$ Article 11 of the FCTC is

(I) School of Public Health \& Health Systems, University of Waterloo. Ontario, Canada.

(2) Propel Centre for Population Health Impact, University of Waterloo. Ontario, Canada. 
dedicated to tobacco product labelling and packaging, including health warnings. As described in section $1 \mathrm{~b}$ of Article 11, health warnings must be no less than 30\%, but "should" cover $50 \%$ or more of the pack, and "may" include pictures. Health warnings must also "rotate", which means that more than one warning should appear on packs either at the same time or over a prescribed time period. The warnings should also be "large, clear, visible, and legible" (table I). The Elaborated Guidelines for Article 11, which are intended to guide implementation of Article 11, provide additional information and recommendations in terms of the type of content, the design of health warnings, as well as the number of warnings and ideal rotation period. ${ }^{2}$ The Elaborated Guidelines also provide a clear recommendation for use of pictorial rather than text-only warnings.

Section 3 of Article 11 also requires packages to include information on "relevant constituents and emissions of tobacco products as defined by national authorities." The Elaborated Guidelines recommend against using numerical information such as "tar" or "nicotine" numbers given that these numbers typically mislead consumers into the false belief that some cigarettes brands with "lower tar" numbers are less harmful than brands with "higher tar" numbers. Instead, the Elaborated Guidelines recommend that countries con- sider more descriptive statements on toxic and addictive components of tobacco products.

\section{Pictorial health warnings}

The introduction of pictorial health warnings is perhaps the most notable regulatory development in product labelling. To date, more than 40 countries have implemented or legislated pictorial warnings on cigarette packages. ${ }^{3}$ The first country to implement pictorial warnings was Canada, in 2000/ 2001 followed by Brazil in 2002. As shown in figure 1, the adoption of pictorial warnings has rapidly accelerated in recent years. For a complete list of pictorial health warnings implemented throughout the world, see www.tobaccolabels.ca.

Table II shows the implementation dates for pictorial health warnings by country. The table also indicates the years in which countries have updated or implemented more recent sets of pictorial warnings. The list of countries in Table II illustrates that implementation of pictorial health warnings is spread across different geographic regions. To date, 13 countries in both the WHO Regions of the Americas and Europe have implemented warnings, followed by 10 countries in the Western Pacific Region. Five countries in the Eastern Mediterranean Region, two countries in South-East Asia, and only one

Table I

\section{WhO Framework Convention on Tobacco Control, Article I I}

Article II: Packaging and labelling of tobacco products

I. Each Party shall, within a period of three years after entry into force of this Convention for that Party, adopt and implement, in accordance with its national law, effective measures to ensure that:

(a) tobacco product packaging and labelling do not promote a tobacco product by any means that are false, misleading, deceptive or likely to create an erroneous impression about its characteristics, health effects, hazards or emissions, including any term, descriptor, trademark, figurative or any other sign that directly or indirectly creates the false impression that a particular tobacco product is less harmful than other tobacco products. These may include terms such as "low tar", "light", "ultra-light", or "mild"; and

(b) each unit packet and package of tobacco products and any outside packaging and labelling of such products also carry health warnings describing the harmful effects of tobacco use, and may include other appropriate messages. These warnings and messages:

I shall be approved by the competent national authority,

II shall be rotating,

III shall be large, clear, visible and legible,

IV should be $50 \%$ or more of the principal display areas but shall be no less than $30 \%$ of the principal display areas,

$\mathrm{V}$ may be in the form of or include pictures or pictograms.

2. Each unit packet and package of tobacco products and any outside packaging and labelling of such products shall, in addition to the warnings specified in paragraph I(b) of this Article, contain information on relevant constituents and emissions of tobacco products as defined by national authorities.

3. Each Party shall require that the warnings and other textual information specified in paragraphs I(b) and paragraph 2 of this Article will appear on each unit packet and package of tobacco products and any outside packaging and labelling of such products in its principal language or languages.

4. For the purposes of this Article, the term "outside packaging and labelling" in relation to tobacco products applies to any packaging and labelling used in the retail sale of the product.

Source: Reference I 


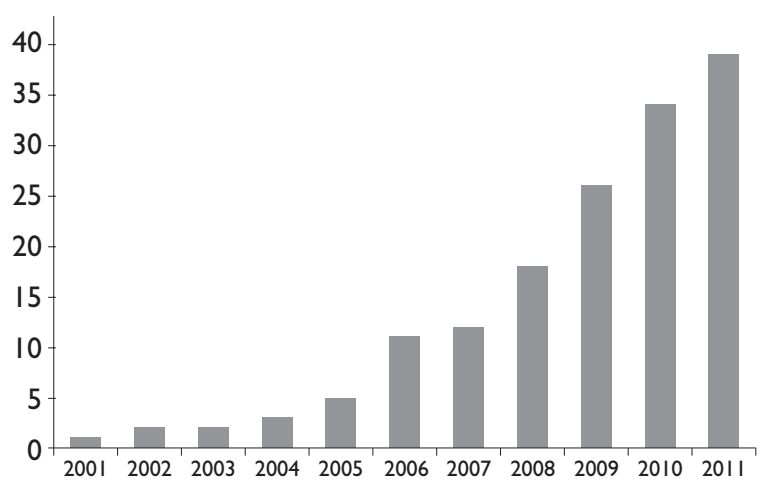

Source: Adapted from reference 3

Figure I. Countries/Jurisdictions ReQUiRing Picture WARNINGS ON CIGARETTE PACKAGES

country in Africa have implemented pictorial health warnings (figure 2).

\section{Health warnings size}

The size of health warnings has steadily increased in a majority of countries. As table III shows, health warnings cover half or more of the package surface in a growing number of countries. Currently, Uruguay has the largest health warnings in the world, covering $80 \%$ of the front and back of packages. Several countries, such as Brazil, include large warnings on only one "face" of the package, where a number of other jurisdictions, including the European Union, include pictorial images on one face and text-only warnings on the other.

\section{Number of warnings and rotation period}

One of the main challenges confronting regulators is the need to periodically update health warnings. Health warnings are not a "static" intervention and, like most other health communications, must be revised or updated to maintain their effectiveness over time. Countries differ with respect to the rotation period -how often one set of warnings is replaced with a new set of warnings or images. There is no clear consensus on the ideal rotation period for warnings. The period may be partly determined by the number of warnings appearing at any one time. In countries such as the United States, the same text-only warnings have appeared on packages for more than 25 years. In contrast, Brazil revised their health warnings in 2002 (9 new warnings), 2004 (10 new warnings), and again in 2008 (10 new warnings). Countries such as Australia have "built-in" rotation periods. Beginning in 2006, Australia identified a total of

Table II

COUNTRIES/JURISDICTIONS REQUIRING PICTURE WARNINGS ON CIGARETTE PACKAGES, BY YEAR OF IMPLEMENTATION

Country (year of implementation*)

\begin{tabular}{|c|c|c|c|c|c|}
\hline I. & Canada $(200 I ; 20 I 2)$ & 16. & Egypt $(2008,2010)$ & 31. & Colombia $(2010)$ \\
\hline 2. & Brazil $(2002 ; 2004 ; 2009)$ & 17. & Brunei (2008) & 32. & Turkey $(2010)$ \\
\hline 3. & Singapore $(2004 ; 2006)$ & 18. & Cook Islands $(2008)^{\ddagger}$ & 33. & Mexico $(2010)$ \\
\hline 4. & Thailand $(2005 ; 2007 ; 2010)$ & 19. & Iran (2009) & 34. & Philippines (20II) \\
\hline 5. & Venezuela $(2005 ; 2009)$ & 20. & Malaysia (2009) & 35. & Norway (20II) \\
\hline 6. & Jordan (2006) & 21. & Taiwan (2009) & 36. & Malta (20II) \\
\hline 7. & Australia (2006) & 22. & Peru (2009) & 37. & France $(20 \mathrm{II})$ \\
\hline 8. & Uruguay $(2006 ; 2008 ; 2009 a ; 2009 b ; 2010)$ & 23. & Djibouti (2009) & 38. & Guernsey (20II) \\
\hline 9. & Panama $(2006 ; 2009)$ & 24. & Mauritius (2009) & 39. & Spain (20II) \\
\hline 10. & Belgium (2006) & 25. & India $(2009,2011)$ & 40. & Bolivia (20II) \\
\hline & Chile $(2006 ; 2007 ; 2008 ; 2009 ; 2010)$ & 26. & Cayman Islands (2009) & 41. & Jersey (2012) \\
\hline 12. & Hong Kong (2007) & 27. & Latvia $(20 \mid 0)$ & 42. & Ukraine (20I2) \\
\hline & New Zealand (2008) & 28. & Pakistan (2010) & 43. & United States (20I2) \\
\hline & Romania (2008) & 29. & Switzerland $(2010)$ & 44. & Argentina (20I2) \\
\hline 15. & United Kingdom (2008) & 30. & Mongolia $(2010)$ & & \\
\hline
\end{tabular}

Source: Reference 3 

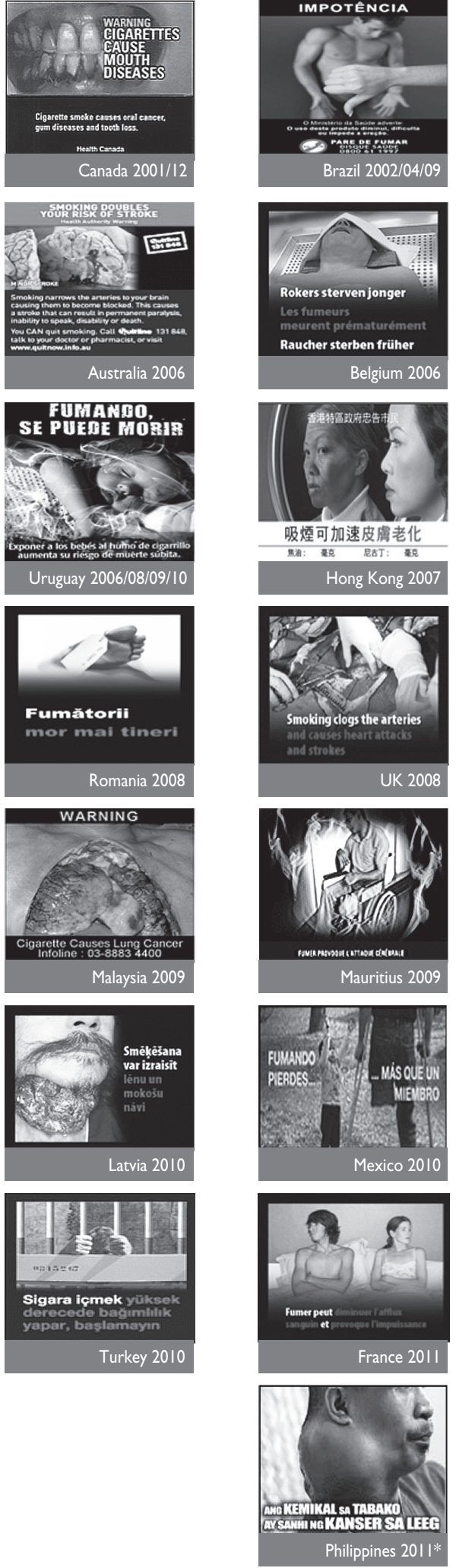
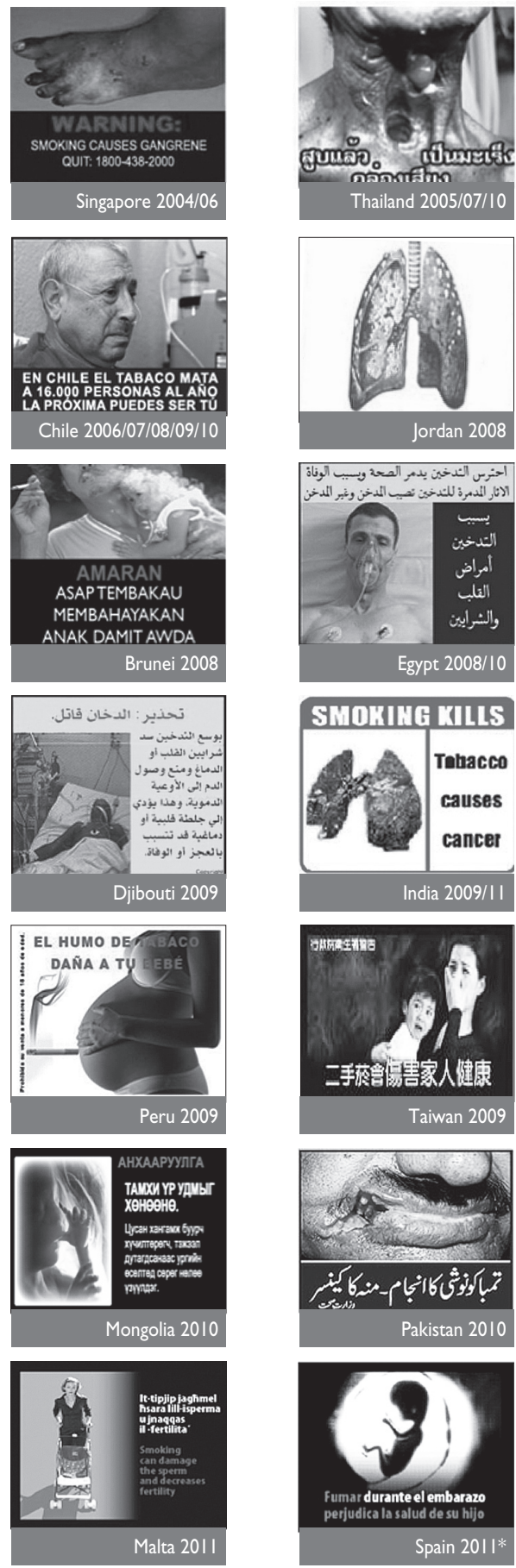

Malta 2011
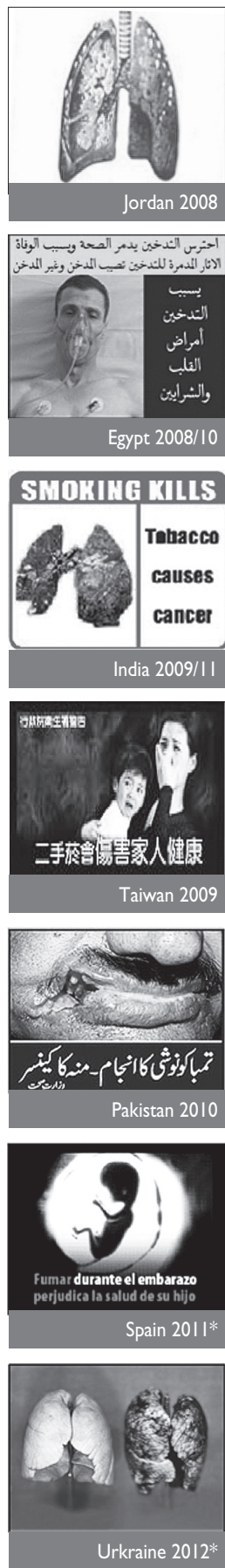
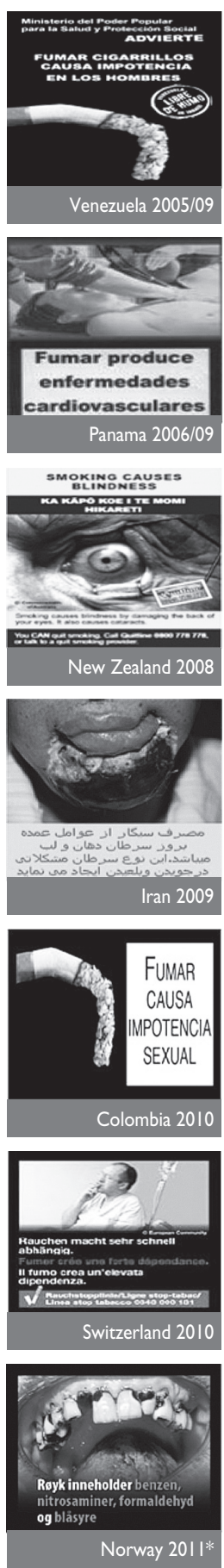

* Proposed implementation date at time of publication

Figure 2. Pictorial health Warnings by country 
Table III

HeALth WARNINGs SIZE - RANKING Of SIZE IN DESCENDING ORDER

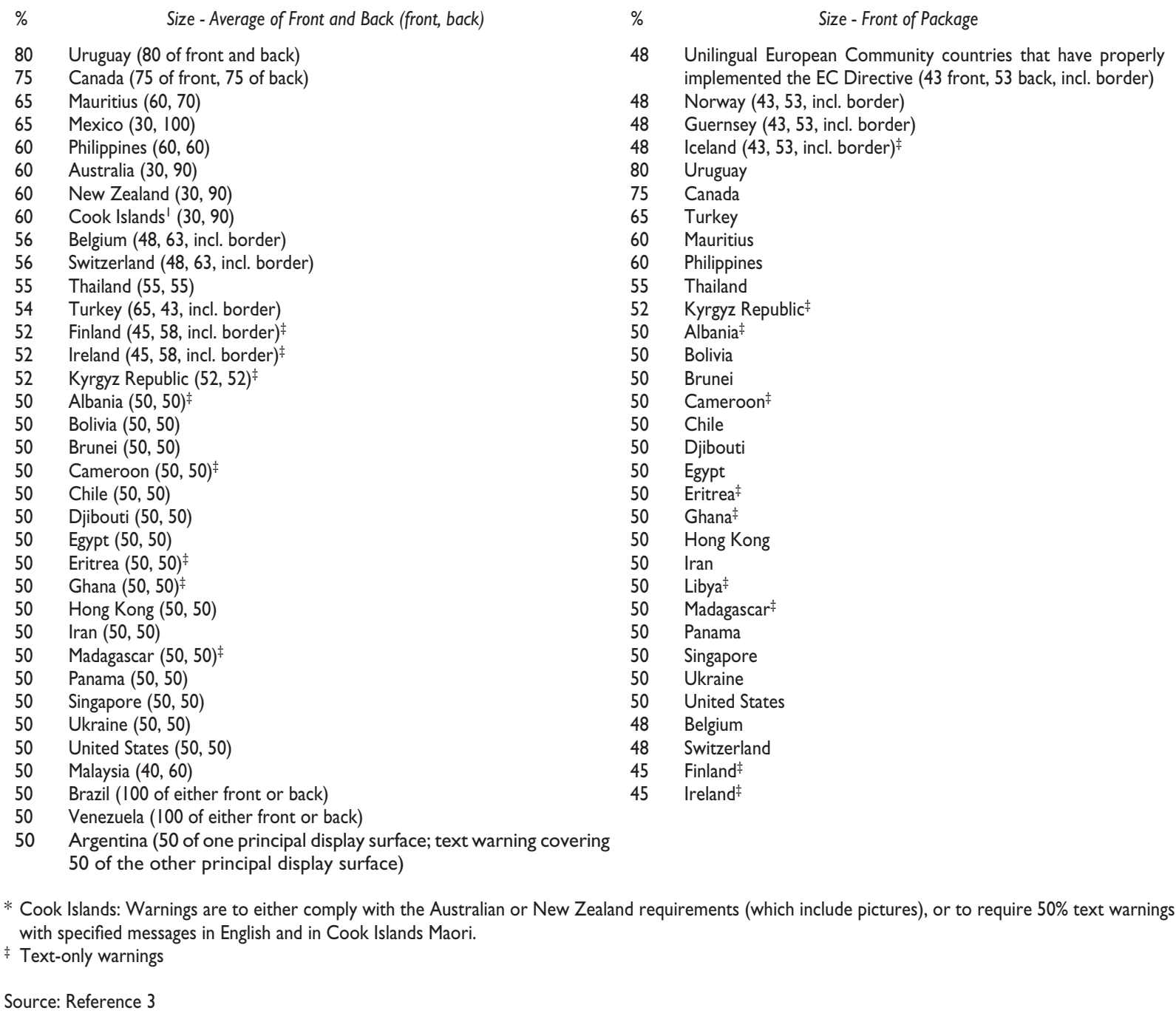

14 warnings, seven of which appeared on packages for 12 months, to be replaced with the "other" seven every 12 months. Switzerland began rotating one set of 14 images starting in 2010 and then a second and third set of 14 images in 2012 and 2014, respectively. Another consideration is whether warnings should be implemented all at once or staggered over a period of time. In 2010, Mexico introduced a novel implementation schedule for eight new pictorial warnings, where two warnings were implemented every three months.

Regulatory practice also differs in terms of the number of warnings in each "set" (i.e., the number of warnings that appear on different packages during the same time period). Countries such as Jordan and Pakistan require only a single warning to appear on packages, whereas Canada requires one of 16 different warnings and the European Union requires one of 14 warnings.

\section{Position, general design and layout}

Health warnings also differ with respect to their general position (top or bottom of pack), as well as design features, such as the amount and placement of text relative to the image size (figure 3). Indeed, some countries require a picture with very little accompanying text. Others, such as Australia and Canada, require pictures with 


\section{Canada}

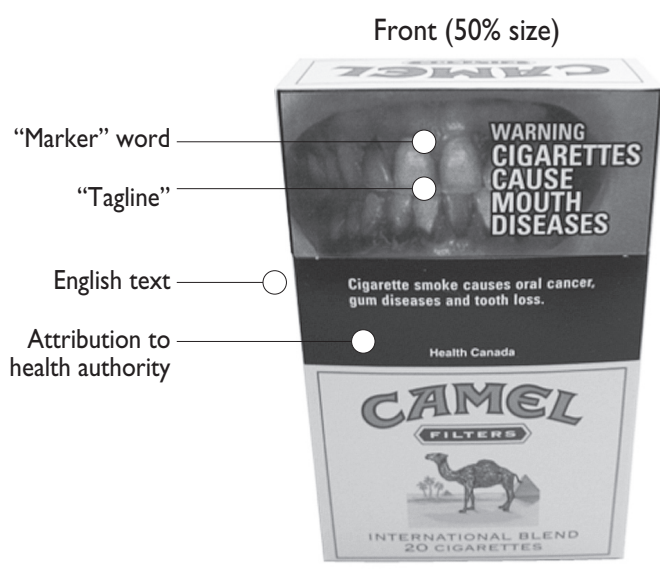

Back ( $50 \%$ size)

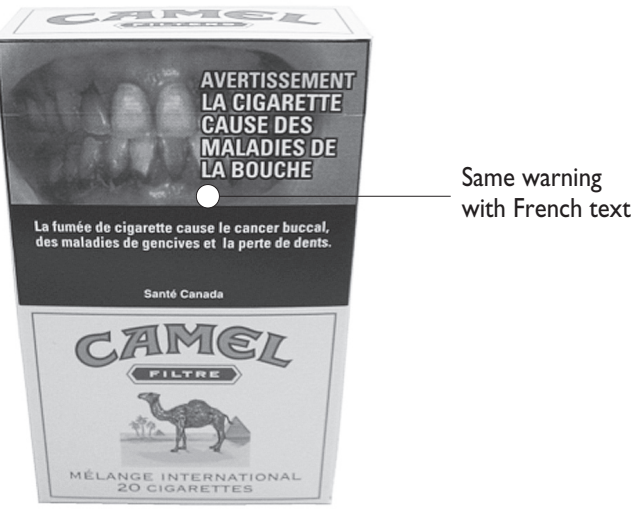

\section{Belgium/European Union}

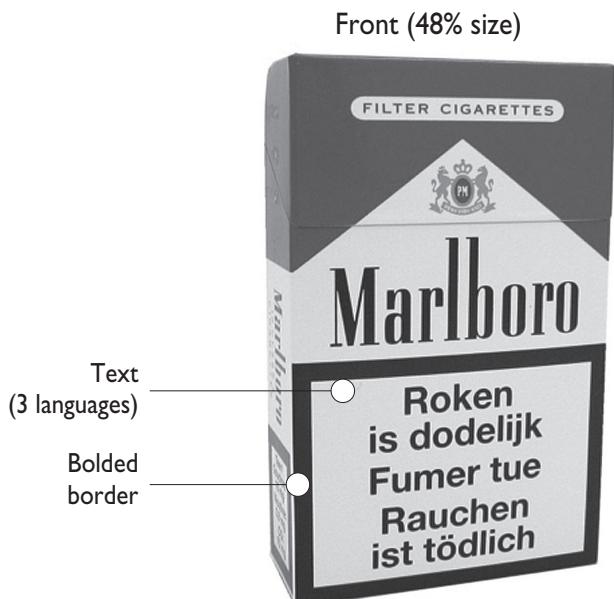

Back (63\% size)

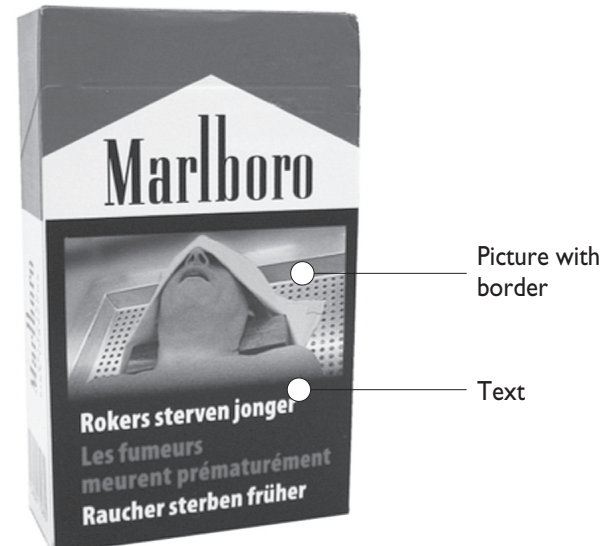

\section{Australia}

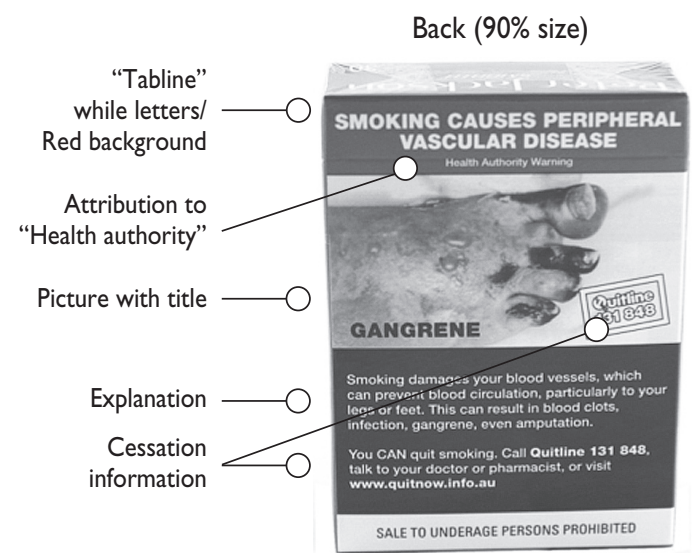

Front (30\% size)

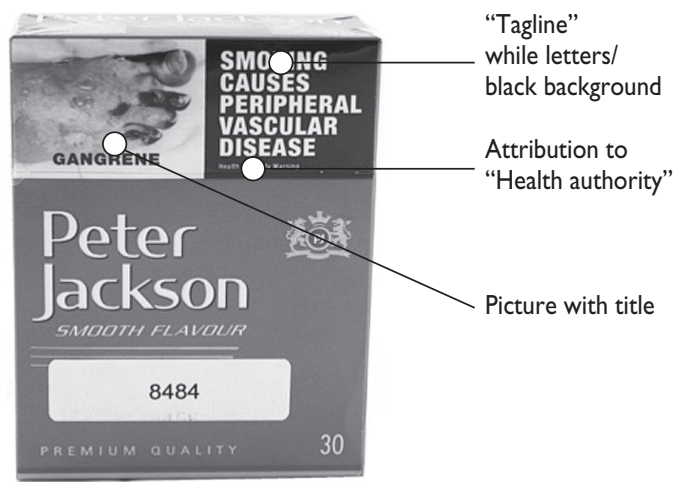

Figure 3. Examples OF Health WARNING LAYOUt AND DESIGN 
a short statement (e.g., "Smoking causes heart disease") with additional explanatory text on the nature and consequences of these risks (explained in more detail below). For pictorial health warnings, the text can be oriented either above or below the image (or both in the case of Australia) or beside the image. The colour of both the text and background also differs across countries. Most countries use contrasting colors, such as white text on a red background, to maximize the legibility of text. Most countries also require a border around the health warning to ensure that the warning is easily distinguishable from the rest of the package.

\section{Message content}

The effectiveness of a health warning is ultimately determined by its content. The most general way to classify the content of health warnings is in terms of the health effect topic or message conveyed in the warning. The most common messages include lung cancer, heart disease, death, addiction, and the risks of second hand smoke, particularly with respect to children and babies. (for a list of pictorial health warnings by health effect, see http:/ / www.tobaccolabels.ca/healthwarningimages). These general topics can be communicated in a number of different ways. As noted above, varying amounts of text can be used to communicate each message. For example, some messages target the perceived likelihood and the perceived severity of health effects- two critical components of risk communication. For example, although many smokers know that smoking causes lung cancer, there are many effective and novel ways to communicate the suffering, loss, and personal experience of lung cancer. From a public health perspective, severity is most often calculated in terms of the number of lives attributable to a particular disease. However, from the individual's perspective, perceived severity may be more closely related to the consequences in terms of quality of life or the consequences to one's physical appearance. For example, the health warning for mouth diseases that originally appeared on Canadian packages in 2000/ 01 has been copied in jurisdictions throughout the world and is among the most recognizable and effective package warning developed to date. This warning is not more effective because mouth disease is any more common or severe than lung cancer or stroke; rather, the mouth disease warning is effective because it depicts a "gross", aesthetically displeasing health effect. To many smokers, "gross" effects to one's physical appearance may be perceived as more severe than more lethal health effects.

\section{Pictorial theme or executional style}

The selection of image is the most important determinant of a health warning's effectiveness. To date, countries have used a wide variety of styles or themes when designing images. These themes can broadly be classified into graphic depictions of health effects (including both "internal" and "externally visible" health effects), the use of testimonials or narratives, the use of symbols and more abstract images, as well as less graphic depictions of human suffering or loss (figure 4).

Recently, the United States became the first country to mandate warnings that feature a "cartoon" / "comic book" style, with hand-drawn panels in the style seen in graphic novels (figure 5) (note these warnings were originally scheduled for implementation in 2012 but have been delayed by tobacco industry legal challenges).

\section{Telephone "quitlines" and cessation services}

A number of countries have integrated information promoting cessation services in their health warnings. Brazil was the first country to include a telephone "quitline" number on health warnings in 2002 (figure 6). Telephone "quitlines" provide free counselling and quit tips to callers, and some may provide access to stop-smoking medications, such as nicotine replacement therapy. A growing number of countries now provide quitline numbers on cigarette packs, including Singapore (2003), Australia (2006), New Zealand (2008) and a number of European jurisdictions. Countries such as Canada have also included a website address for smokers to access information. For many countries that lack a national quitline, website information may be a more feasible alternative for linking smokers with effective cessation services.

Inserts and "interior" warnings

To date, Canada is the only country to require "supplemental" health messages on the inside of packages (figure 7). Beginning in 2012, the existing interior messages will be expanded and one of eight warning messages will be required as an insert or on the inside panel of packages. ${ }^{4}$ These messages provide additional health information, as well as advice on cessation and sources of support. Using inserts or "onserts" (messages fixed to the outside of packs) provides regulators with additional opportunities to communicate with smokers, but has been largely unstudied. ${ }^{5}$ 


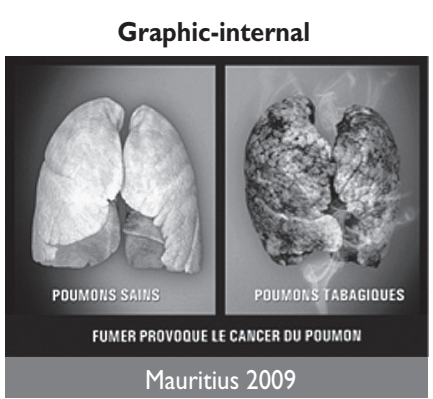

Lived experience-other

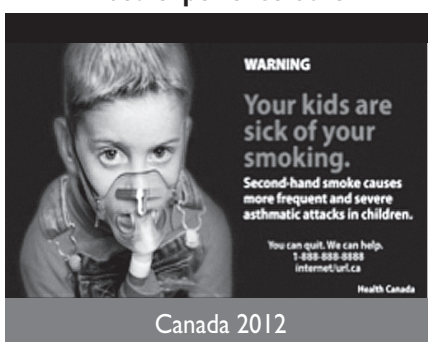

Graphic-external

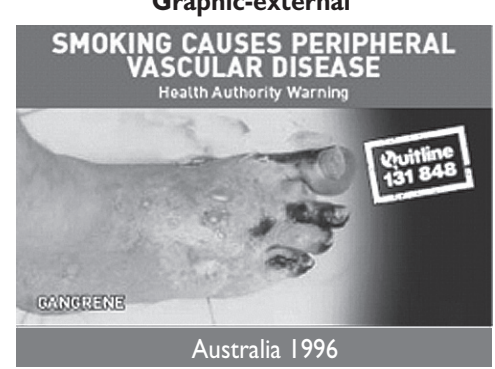

Testimonial

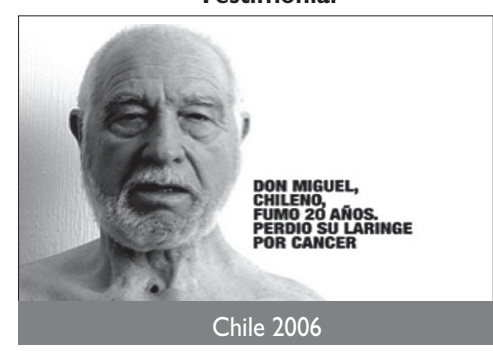

Lived experience-selft

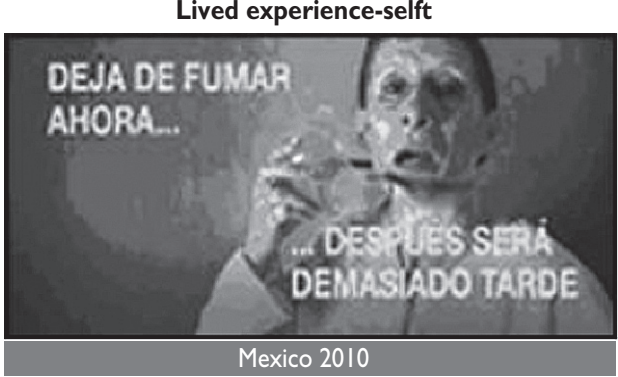

Symbolic

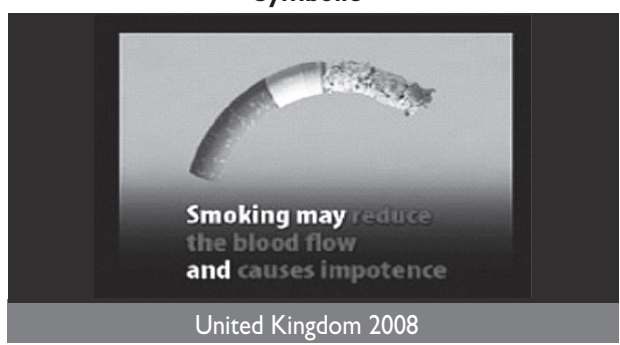

Figure 4. Examples of Pictorial health WARNing themes
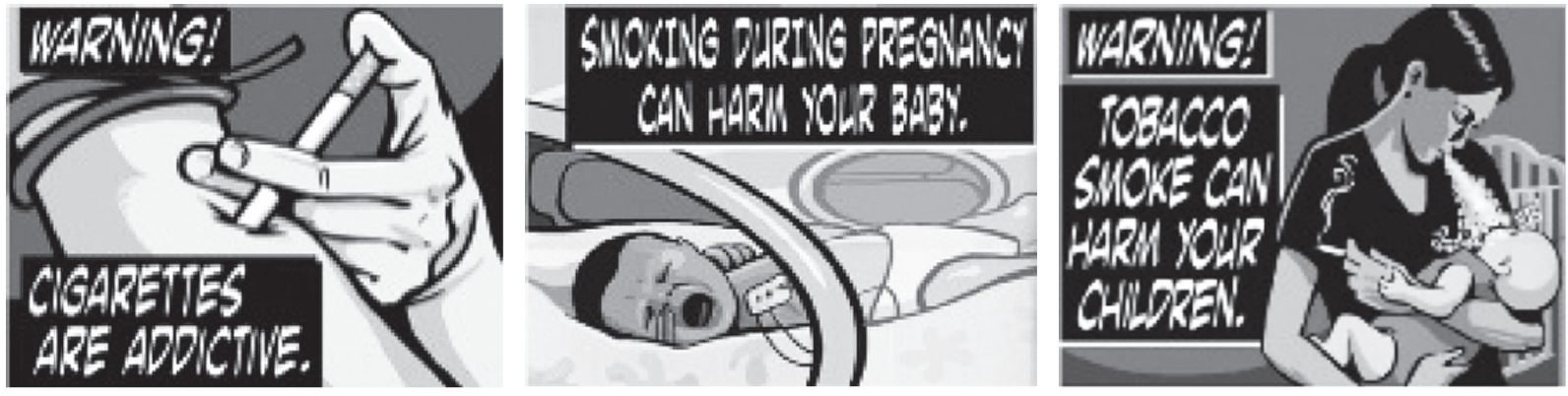

Figure 5. “Cartoon” images (United States)

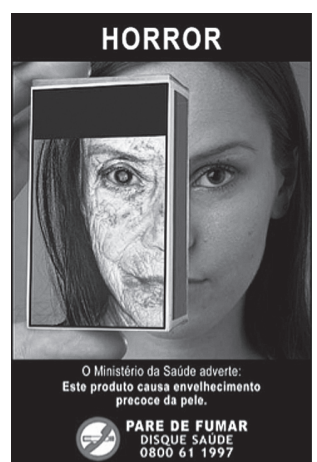

FigURE 6. EXAMPLE OF QUITLINE INFORMATION INTEGRATED IN HEALTH WARNING (BRAZIL 20I0)
Source attribution

Warnings in many countries also include text attributing the health warning to the government or some other source. Often, the name of the health ministry is included in small letters at the end of the warning. In other cases, the attribution is included as part of the preamble to the warning, such as: "The Department of Health and Welfare advises...". In countries where the government health ministry is well regarded and has high credibility, attribution to a government source may increase the believability of the information; however, if the government is generally disliked or mistrusted, attribution to government sources may result in rejection of the health warning. 


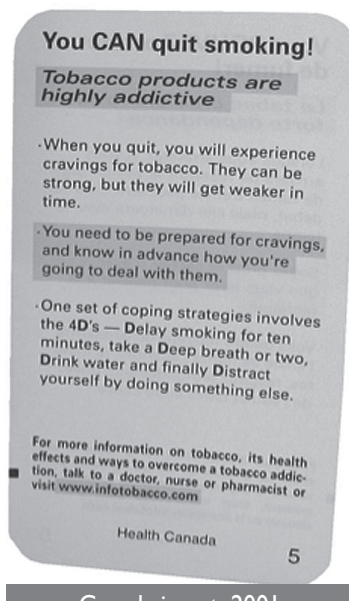

Canada insert, 200I

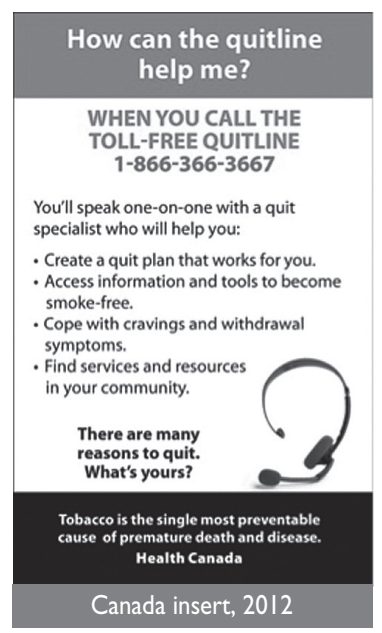

Figure 7. Inserts AND INTERIOR WARnings (CANADA)

\section{Constituent and emission labelling}

Article 11 states that, in addition to the "main" health warnings, tobacco products shall "contain information on relevant constituents and emissions of tobacco products as defined by national authorities". ${ }^{1}$ Cigarette smoke contains approximately 4000 chemicals, includ-

ing over 60 carcinogens. ${ }^{6}$ Communicating this information to consumers in a meaningful way has proven to be a significant challenge.

Currently, a number of jurisdictions require tar, nicotine, and carbon monoxide emissions to be printed on packages (figure 8). These numbers are derived from smoking machines (using either the ISO or FTC smoking regimens) and represent neither the amount of chemicals present in the tobacco itself nor the amounts actually ingested by human smokers. The current scientific consensus is that emissions numbers do not accurately reflect meaningful differences in risk between conventional cigarette brands. ${ }^{7}$ Alternative approaches to communicating the basic ISO tar and nicotine amounts, such as adding a set of higher numbers from more intensive smoking regimens have proven equally misleading and confusing to consumers. ${ }^{8}$

Based on the scientific consensus that tar and other emission numbers are misleading, the Elaborated Guidelines for Article 11 recommend that: "Parties should prohibit the display of figures for emission yields, such as tar, nicotine and carbon monoxide, on packaging and labeling, including when used as part of a brand name or trademark". ${ }^{2}$ A growing number of countries have removed numerica emission information from packages and replaced it with descriptive information about toxic constituents and their effects on health, including Brazil, Australia, and most recently, Canada.
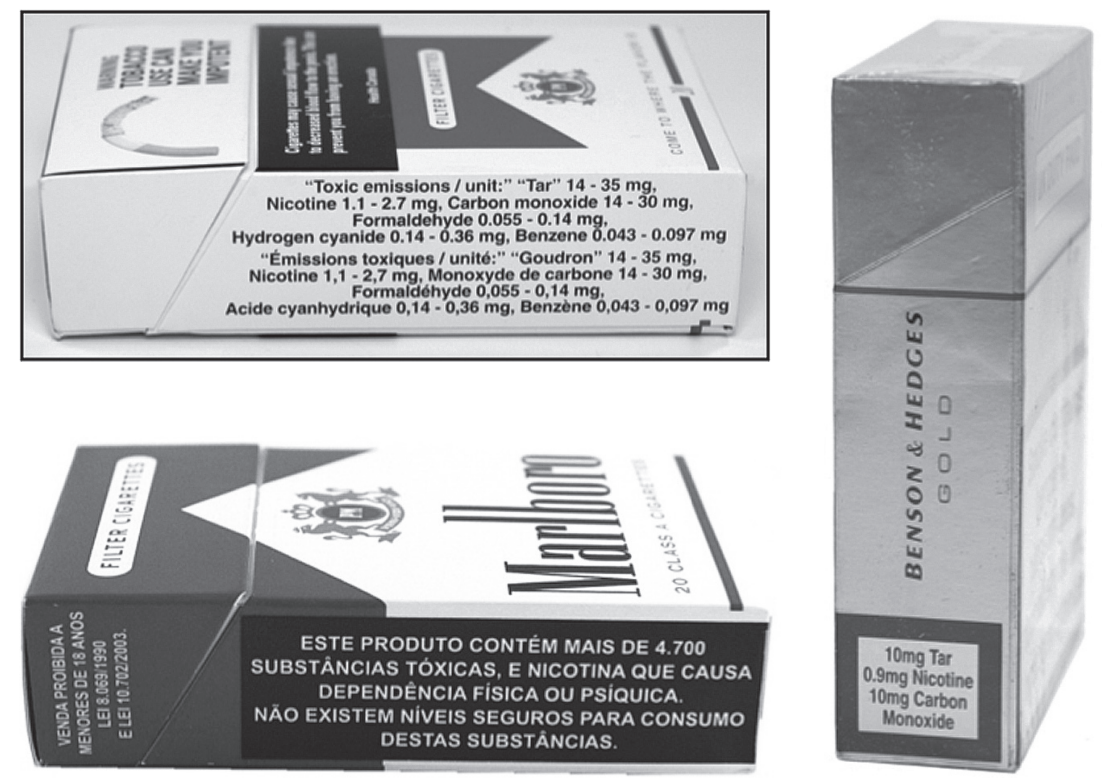

Figure 8. Examples of emission labelLing 


\section{Implementation and mass media campaigns}

The introduction of new health warnings and messages represents an excellent opportunity to link and leverage other policy initiatives. Where resources allow, mass media initiatives can be timed to coincide with the new messages appearing on the market. A coordinated media campaign will reinforce warnings and messages, improve access to target groups, provide additional information on health warnings and messages and also communicate other information that increases tobacco users motivation and confidence in their ability to quit, such as the benefits of quitting, attitudes towards quitting, quit advice and contact details of quit organizations. For example, one of the pictorial health warnings implemented in Australia included a theme and subject that was also featured in a very successful and well known television campaign depicting the effects of smoking on arteries. Incorporating the same theme and subject in the package warnings (figure 9) provided an opportunity to capitalize upon this successful campaign and to provide constant reminders to smokers.

New South Wales, one of the five Australian states, has also used the health warning messages as a basis for advertisements on the side of busses (figure 10), as well as several television spots. In both the bus and television spots, the advertisements have helped to make the information in health warnings more vivid and provided a compelling narrative to the pictures and text. Smokers who see these advertisements are likely to recall them each time they see the related images on the pack.

\section{Health warnings on smokeless tobacco and "other" tobacco products}

Non-cigarette products, including smokeless tobacco, cigars, bidis, and shisha or waterpipe, are typically subject to fewer product labelling regulations. In most countries

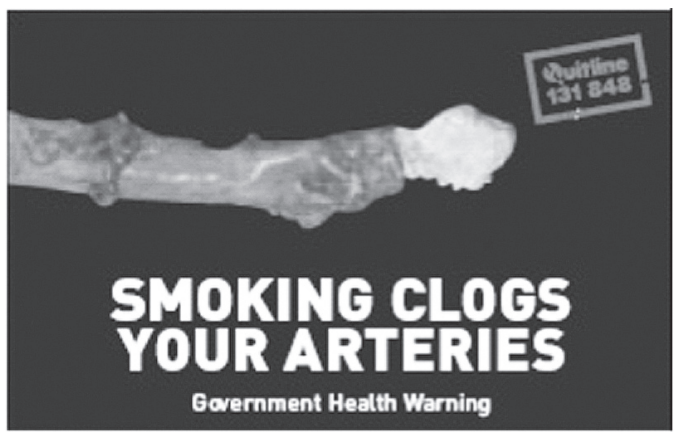

Figure 9. Australian health Warnings and mass media CAMPAIGNS in which both cigarettes and smokeless tobacco products are sold, smokeless products require smaller, less prominent warnings. To date, India is the only country in the world to require pictorial health warnings on smokeless tobacco products (figure 11). These products may require unique content in terms of health effects and may also present challenges in terms of different forms of packaging. In the case of waterpipes, the warning could be placed on the waterpipe itself or on the tobacco or "hagar". Smokeless tobacco products are often sold in non-standardized packaging, with a wide range of shapes, which can make it difficult to identify a "front" and "back" or primary surface area.

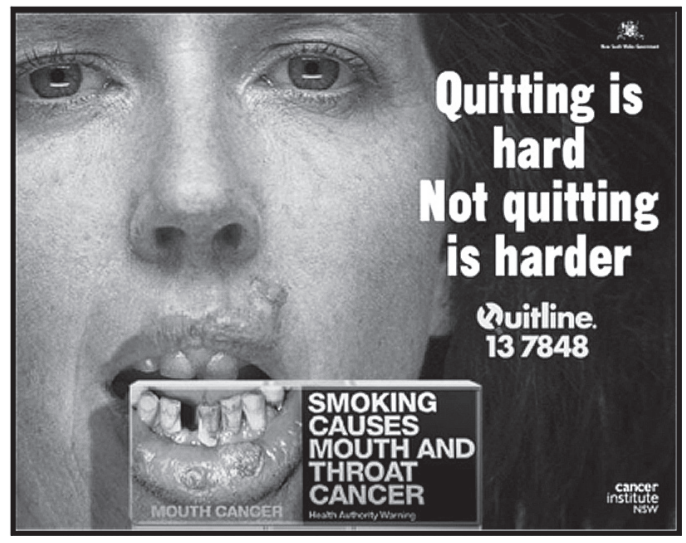

Figure I0. Australian health WARNings AND MASS MEDIA CAMPAIGNS

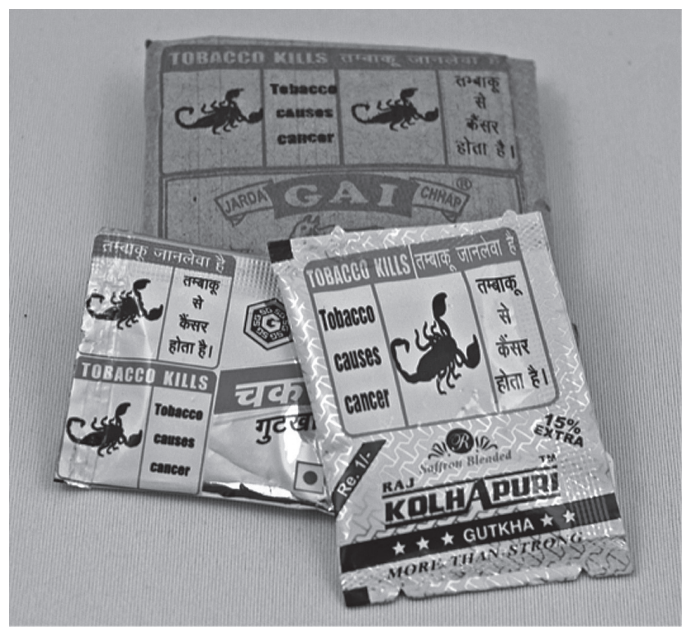

Figure I I: Pictorial warnings on smokeless tobacco PRODUCTS (INDIA) 
Declaration of conflict of interests: The authors declare not to have conflict of interests.

\section{References}

I. World Health Organization. WHO Framework Convention on Tobacco Control. [Internet]. Geneva: World Health Organization 2003. Available at: http://www.who.int/tobacco/framework/en/

2. World Health Organization. Framework Convention on Tobacco Control. Elaboration of guidelines for implementation of Article II of the Convention. (2008) Available at: http://apps.who.int/gb/ftc/PDF/cop3/ FCTC_COP3_7-en.pdf

3. Cunningham R. Cigarette Package Warning Size and Use of Pictures: International Summary. Canadian Cancer Society; October 5, $201 \mathrm{I}$. Available at: http://www.tobaccolabels.ca/healthwarnings/statusreport 4. Health Canada. Tobacco products labelling regulations (cigarettes and Little cigars). Ottawa, Health Canada. Available from.http://www.hc-gc. ca1/hc-ps/tobac-tabac/legislation/reg/label-etiquette/index-eng-php.
5. Hammond D, Fong GT, McDonald PW, Cameron R, Brown KS. The impact of the graphic Canadian warning labels on adult smoking. Tob Control 2003;12:39|-395.

6. Hoffmann I, Hoffmann D. The changing cigarette: chemical studies and bioassays. In: Boyle P, Gray N, Henningfield J, et al, eds. Tobacco: science, policy and public health. New York: Oxford University Press, 2004:53-92. 7. World Health Organization. Study Group on Tobacco Product Regulation. Guiding principles for the development of tobacco research and testing capacity and proposed protocols for the initiation of tobacco product testing. (2004) Available at: http://www.who.int/tobacco/global_ interaction/tobreg/goa_2003_principles/en/index.html

8. Environics Research Group. Summary report of four focus groups in Toronto \& Montreal on awareness and understanding on toxic emissions information on tobacco packaging. Toronto (ON): Environics Research Group Limited; March 2003. I5 p. Report No.: PO 02-95/H4097-025030/00I/CY PN5303. Prepared for Health Canada. 